\title{
O Movimiento Nacional de Victimas de Crimenes de Estado (MOVICE): Uma luta independente e alternativa por um projeto democrático colombiano baseado nos princípios de memória, verdade, justiça e reparação
}

\author{
The Movimiento Nacional de Victimas de Crimenes de \\ Estado (MOVICE): An independent and alternative struggle for \\ a Colombian democratic project based on the principles of \\ memory, truth, justice and reparation
}

Laura Milena Guerrero

Mestranda em Sociologia Política (Universidade Federal de Santa Catarina)

lauraguerrero@yahoo.com

\begin{abstract}
Resumo:
Durante o segundo "Encontro Nacional de Vítimas de Crimes de Lesa Humanidade em Bogotá Colômbia", em 2005, promovido quatro dias após a aprovação da lei de "Justiça e Paz", com a qual o governo colombiano institucionalizou um marco jurídico que permitisse a reinserção dos Paramilitares à vida civil, nasceu o MOVICE: "Movimento Nacional de Vítimas de Crimes de Estado". O texto aqui apresentado tem como objetivo analisar o MOVICE como uma rede de movimentos sociais na qual se constroem significados comuns entre diversas organizações formadas com objetivos, estruturas e atores diferentes. Procura-se também evidenciar que suas demandas e ações podem ser interpretadas desde uma perspectiva teórica pós-colonial, na medida em que sua luta pela memória das vítimas retroalimenta os debates e avanços das novas narrativas sobre movimentos sociais na Colômbia.
\end{abstract}

Palavras chave: MOVICE. Crimes de Estado. Colômbia. Pós-Colonialismo. Movimento Social.

\begin{abstract}
:
During the second "National Meeting on Victims of crimes against humanity in Bogota - Colombia" in 2005, held four days after the passage of the law of "Justice and Peace," in which the Colombian government has institutionalized a legal framework that would allow reinsertion of paramilitaries into civilian life, was born MOVICE: "National Movement of Victims of State Crime". The text presented here is to analyze the MOVICE as a network of social movements in which we construct shared meaning among various organizations formed with goals, structures, and different actors. We also search is for evidence that their demands and actions can be interpreted from a postcolonial theoretical perspective, in that their fight for the victims feeds back the progress of discussions and new narratives about social movements in Colombia.
\end{abstract}

Keywords: MOVICE. Crimes of State. Colombia. Postcolonialism. Social Movement.

Originais recebidos em: 01/07/11

Aceito para publicação em: 05/08/11

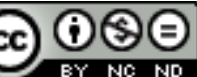
Comercial-Vedada a criação de obras derivadas 3.0 Unported License 


\section{Introdução}

Durante o segundo "Encontro Nacional de Vítimas de Crimes de Lesa Humanidade em Bogotá - Colômbia”, que contou com a participação de mais de 800 delegados de 200 organizações locais de diferentes cidades do país, promovido exatamente quatro dias após a aprovação da lei no 75 de 2005 intitulada "Justiça e Paz", com a qual o governo colombiano institucionalizou um marco jurídico que permitisse a reinserção dos Paramilitares à vida civil, nasceu o MOVICE: "Movimiento Nacional de Victimas de Crímenes de Estado". Dito organismo surgiu como uma rede de movimentos e organizações nacionais distintos que contou com o apoio de múltiplas organizações internacionais. O grupo se formou pela necessidade dos movimentos e organizações buscarem uma verdade autêntica, assim como justiça e reparação integral para vítimas do Estado colombiano.

Ainda que o propósito inicial do MOVICE seja lutar contra a impunidade do Estado e pela dignificação das vítimas do conflito armado e social na Colômbia, suas ações e reivindicações evidenciam uma luta independente e alternativa por um projeto democrático mais abrangente.

Nele, busca-se que sejam reconhecidas as memórias e direitos de todos onde seja possível uma nova significação do passado no processo de construção de uma identidade nacional mais ampla e legítima.

O texto aqui apresentado tem como objetivo analisar o MOVICE como uma rede de movimentos sociais na qual se constroem significados comuns entre diversas organizações formadas com objetivos, estruturas e atores diferentes. Procura-se também evidenciar que suas demandas e ações podem ser interpretadas desde uma perspectiva teórica pós-colonial, na medida em que sua luta pela memória das vítimas retroalimenta os debates e avanços das novas narrativas sobre movimentos sociais no país.

\section{Antecedentes do surgimento do Movimento}

O "Movimiento de Victimas de Crimenes de Estado" (MOVICE) é uma rede de organizações integrada por pessoas e movimentos sociais com objetivos, estruturas e estratégias de ação diferentes. Estes coletivos se juntaram em torno de uma identidade política comum com o objetivo de se mobilizarem, principalmente, contra os crimes 
praticados pelo Estado colombiano contra os direitos humanos, exigindo, em contrapartida, que sejam praticados valores como a verdade, a justiça e a reparação das vítimas destes crimes. Sua aparição é o resultado do encontro de diversas campanhas e mobilizações conjuntas promovidas por distintas organizações de vítimas que, por mais de meio século, sofreram com confrontos armados e a violência sistemática da história colombiana.

Nos anos noventa do século XX, a consolidação de uma nova Constituição ${ }^{1}$ inaugurou um Estado Social de Direitos na Colômbia na mesma época em que, paradoxalmente, o país passava por uma forte e sistemática sequência de violações dos direitos humanos. Este cenário foi marcado pela atuação de organizações paramilitares. ${ }^{2}$ Como resposta a esta realidade, algumas das vítimas, suas famílias e organizações afins começaram a se mobilizar e a tornar mais visíveis as suas insatisfações e exigências de reparação na vida pública. Nesse contexto surgiu o projeto "Colombia: Nunca Más Crímenes de Lesa Humanidad" por iniciativa de 17 organizações diversas (de direitos humanos, indígenas e de vítimas da violência) com o objetivo de denunciar e recuperar a memória das vítimas da última etapa da violência vivida no país.

Essa iniciativa seguia a linha geral de outros projetos lançados anteriormente, como o "Nunca Mais", na América Latina. A principal diferenciação do projeto colombiano residia, especialmente, no fato de que ele não surgiu em um contexto de pós-ditadura ou pós-guerra civil, mas, diferente dos demais, ele foi criado dentro de uma realidade de confronto armado e civil contemporâneo caracterizado pela prática permanente de crimes contra os direitos humanos praticados por parte do Estado e de atores ilegais atuantes no país. Ainda que o projeto tenha enfrentado múltiplas

1 A Constituição de 1991, que substituiu a anterior, instituída em 1886, reconheceu os direitos individuais e coletivos dos colombianos. Declarou a nação como um Estado Social de Direitos organizado em forma de república unitária descentralizada, com autonomia de suas entidades territoriais, e a declarou como uma nação democrática, participativa e pluralista.

2 O paramilitarismo é um fenômeno complexo no contexto colombiano. Sua origem encontra-se na luta contra- insurgente no marco do impulso dos princípios da Doutrina de Segurança Nacional e Conflitos de Baixa Intensidade. O Estado, através de suas forças militares e em conjunto com setores sociais, econômicos e políticos regionais, promoveu e atuou como agente dinamizador da formação do paramilitarismo (MEDINA, 1990). Em 1997, foram criadas as Autodefesas Unidas de Colômbia (AUC), uma organização através da qual foram reunidos e organizados os grupos regionais paramilitares com uma estrutura relativamente centralizada, reunindo um número aproximado de mais de 30.000 homens. Os paramilitares têm sido identificados como os responsáveis por uma enorme quantidade de massacres, desaparecimentos, assassinatos e outros crimes praticados contra os direitos humanos (AMNISTIA INTERNACIONAL, 1994). Entre 2002 e 2006, as AUC participaram de um processo de reintegração à vida civil conhecido como processo de "desmovilización" através de um acordo com o governo nacional. Mas as atuações destes grupos e os crimes praticados por eles contra os direitos humanos continuam sendo feitos em algumas regiões do país através de organizações emergentes. Para mais informações, ver Medina (1990), Jaramillo (2005) e Tobon, Granada e Restrepo (2009).

Em Debat: Rev. Dig., ISSNe 1980-3532, Florianópolis, n. 6, p. 230-245, jul-dez, 2011. 
dificuldades, como a perseguição e a criminalização por parte do governo de algumas das organizações que faziam parte dele, assim como o surgimento de disputas internas relacionadas com divergências políticas entre seus atores, ele se configurou como uma das grandes iniciativas que, posteriormente, dariam base para o surgimento do MOVICE.

Igualmente significativa para a consolidação do movimento foi a campanha “Colombia Clama Justicia”, lançada em 1998, e através da qual foram estabelecidos os tribunais de opinião com o objetivo de esclarecer os fatos relacionados com os massacres ocorridos nos dias 16 de maio de 1998 em Barrancabermeja $^{3}$, 13 de dezembro de 1998 em Santo Domingo ${ }^{4}$, e outras centenas de outros crimes cometidos entre os anos 1993 e 2003 na região Sul do departamento ${ }^{5}$ de Bolívar (MOVICE, 2010).

Essa campanha possibilitou o fortalecimento de algumas organizações regionais que chamaram a atenção da opinião pública internacional sobre os crimes praticados contra os direitos humanos na Colômbia.

No encerramento do primeiro encontro Nacional de Vítimas de Crimes de Lesa Humanidade e Violação aos Direitos Humanos, realizado em Bogotá em maio de 2004, as organizações presentes no evento decidiram avançar na criação de um movimento nacional que unisse as diferentes organizações, pessoas, famílias e coletivos de vítimas de crimes de Estado. Pouco depois, nas assembleias regionais preparatórias para o segundo Encontro Nacional, o MOVICE começou a se estruturar; primeiro na eleição de representantes e, posteriormente, na definição de linhas de trabalho e ação conjuntas.

\section{O MOVICE como uma Rede de Movimentos Sociais}

Segundo Scherer-Warren (2006), uma Rede de Movimentos Sociais, como categoria teórica de análise, implica a identificação de sujeitos coletivos em torno de valores, objetivos ou projetos em comum. A definição de atores ou situações sistêmicas antagônicas devem, neste contexto, ser combatidas e transformadas para a definição de

3 Massacre de 37 civis realizado pelos paramilitares das "Autodefensas Unidas de Santander y Sur de Cesar AUSAC" em Barrancabermeja, cidade do departamento de Norte de Santander, na Colômbia.

4 Fato ocorrido em Santo Domingo, pequena cidade pertencente ao município de Tame, no departamento de Arauca, no qual as Forças Militares do Exército Colombiano (FAC) bombardearam a população civil por um proclamado "erro militar", assassinando 17 camponeses (sendo 6 crianças) e ferindo outras 25 pessoas. Por esse crime a Justiça colombiana condenou por homicídio culposo a três militares no ano de 2007.

5 Os departamentos são organizações político-administrativas nas quais está dividido o território colombiano.

Em Debat: Rev. Dig., ISSNe 1980-3532, Florianópolis, n. 6, p. 230-245, jul-dez, 2011. 
um mesmo projeto ou utopia. Desta forma, o MOVICE é entendido como uma rede de movimentos que se identifica na ideia comum de vítima; opondo-se ao Estado, este visto como estrutura de violação de direitos humanos; e atuando na proposição de um novo projeto de país baseado nos princípios de justiça, verdade, reparação, não repetição dos crimes denunciados e da memória.

\section{As vítimas da violência configuradas como um ator político plural}

A consolidação de um projeto comum no MOVICE é baseada no conceito de vítimas. Nesse sentido, sua identidade política é abrangente. Dela fazem parte pessoas e coletivos provenientes de diversas classes sociais, gêneros, etnias e gerações. Segundo definição do próprio movimento, ele está conformado por mulheres e homens, comunidades de diversas origens étnicas, culturais e geracionais, organizações sindicais e políticas que viveram o impacto da violência gerada pelo Estado colombiano através da prática de crimes massivos e sistemáticos contra os seus direitos individuais e coletivos, políticos, econômicos, sociais e culturais (MOVICE, 2010).

É importante enfatizar sobre a conformação plural do movimento. O MOVICE se configura como multicultural e multiétnico já que dele participam organizações camponesas, indígenas, afro-descendentes, entre outras, assim como no grupo existe uma presença ativa de homens e mulheres provenientes de diferentes tipos de organizações políticas. Esta configuração é possível na medida em que a identidade comum do movimento é estabelecida através de uma categoria mais abrangente, a de vítima, na qual podem ser incluídas muitas outras. Assim, o MOVICE, como tantos outros movimentos sociais atuais, cria uma identidade coletiva ampla que the permite ter uma maior visibilidade pública, permitindo que o movimento possa lutar com maior eficácia pela dignificação e restituição dos direitos de cidadãos e, dessa forma, ter mais possibilidades de transformação social (SCHERER-WARREN, 2008).

A autodeterminação como vítimas é o elo central na bandeira do movimento, o que termina por determinar sua luta e seu projeto de ação. O MOVICE redefine, desta forma, a categoria de vítima como um ator social e político de direitos que ultrapassa a lógica estabelecida pelas políticas estatais, pelas quais as vítimas são geradas unicamente por ação dos grupos armados ilegais. 
O conceito de vítima, adotado pelas políticas estatais e detalhado na Lei $n^{\circ} 975$ de 2005, faz referência unicamente à pessoa ou coletivo que tenha sofrido danos diretos, como lesões temporais ou permanentes que gerem algum tipo de incapacidade física, psíquica ou sensorial, sofrimento emocional, perda financeira ou privação de direitos fundamentais como consequência de ações que transgrediram a legislação penal e que foram praticadas por grupos organizados fora da lei ${ }^{6}$.

Note-se que a vítima, na descrição da lei, só pode ser considerada como resultado de ações dos grupos armados fora da lei, mas nunca pelo Estado. Assim, quando o MOVICE se proclama como uma organização de vítimas do Estado, o movimento está estabelecendo uma crítica profunda ao sistema social e político atual, definindo as vítimas como o resultado direto de uma estrutura sociopolítica excludente. A partir da configuração como coletivo de vítimas de crimes de Estado, o movimento avança também na definição da situação e dos atores contra os quais a sua luta se dirige. Coloca-se, desta forma, contra as práticas de violência sistemática e generalizada realizadas pelo Estado ou por outras estruturas organizadas amparadas por ele, como é o caso do paramilitarismo, opondo-se ainda ao sistema hegemônico no qual têm-se mantido sistemas de homogeneização, esquecimento e de opressão por meio da violência.

\section{Atuação na conquista e construção dos direitos das vítimas, assim como na consolidação de uma democracia abrangente}

O projeto ou utopia do MOVICE se fundamenta na consolidação de uma cidadania real para as vítimas e na instituição de um projeto de país baseado na busca de uma memória abrangente. A transversalidade dos direitos nas lutas dos movimentos sociais ou das novas formas de organização da sociedade civil é ressaltada por vários autores (SCHERRER-WARREN, 2008; HALL, 2003). Estes teóricos apontam que a tendência dos movimentos sociais nas sociedades complexas atuais é o de conquistar os direitos humanos através de seu reconhecimento e determinação de sua garantia por parte do Estado ou, ainda, de construir estes direitos no sentido de lhes dar um novo significado e de conseguir sua efetivação mesmo à margem da atuação dos Estados.

6 Artigo 5, da Lei $n^{0}$ 975, de 2005, pela qual se estabelecem disposições para a reincorporarão de membros de grupos armados organizados fora da lei que contribuam de maneira efetiva para a efetivação da paz nacional e no qual se estabelecem outras disposições para acordos humanitários. 
Entendendo que as atuações dos denominados "novos movimentos sociais" estão orientadas por questões éticas, de cidadania, participação política e novas formas de representação dos atores sociais ou de expressão de identidades culturais e sociais (MELUCCI, 2001), podemos concluir também que sua luta está dirigida à conquista e construção de uma nova geração de direitos econômicos, sociais, políticos e culturais relacionados com minorias étnicas, sustentabilidade sócio-ambiental local e global, o reconhecimento da diferença, entre outros (KAUCHAKJE, 2008).

O MOVICE, por sua parte, ressalta os direitos das vítimas priorizando a verdade, a justiça, a reparação, a não-repetição de crimes e, especialmente, a memória. Esses direitos não são entendidos de maneira independente; estão intimamente relacionados entre si e são transversais à toda sua luta. Quando o movimento exige verdade e justiça pede, desta forma, o esclarecimento das circunstâncias e condições pelas quais algumas pessoas e setores da sociedade foram excluídos e violentados, assim como exige o julgamento e a condenação dos responsáveis por estes atos. Quando ele exige reparação integral, faz referência ao ressarcimento tanto material quanto simbólico para cada uma das pessoas e coletivos afetados pelas políticas e atuações do Estado. E quando estabelece os princípios da não-repetição e memória das vítimas, conclama por uma mudança estrutural na atuação do Estado solicitando a consolidação de um projeto novo de país, baseado em uma democracia abrangente e participativa na qual seja reinterpretado o passado e o pressente de cara às memórias e histórias esquecidas ou não hegemônicas.

Para entender sua luta, analisaremos nas páginas seguintes algumas das formas de atuação do MOVICE e seu nível de empoderamento, o qual nos permitirá, no final do texto, retomar o tema da memória que, por sua vez, propiciará perceber o movimento desde uma abordagem pós- colonial.

\section{Estratégias de atuação e nível de empoderamento}

Para a consolidação de seus objetivos, o MOVICE tem desenvolvido uma ampla gama de atuações. Ainda que sua postura seja divergente das dinâmicas estatais atuais, o movimento tem desenvolvido ações através das estruturas do Estado, especialmente das políticas públicas. Ao mesmo tempo, ele tem se afastado destas estruturas, tentando permanecer como um agente de pressão autônomo da sociedade civil. O 
desenvolvimento desse repertório foi se construindo historicamente e vai-se desenvolvendo segundo problemáticas e objetivos pontuais.

No terceiro Encontro Nacional de Vítimas de Crimes de Estado, o MOVICE estruturou sua atuação por meio de oito estratégias através das quais o movimento avança na consolidação do seu projeto. Essas estratégias são: jurídica; verdade e memória histórica; acompanhamento solidário com as vítimas ou comissão ética; nãorepetição; reparação; luta contra a desaparição forçada; luta contra o genocídio político; e uma estratégia organizativa ou de fortalecimento do movimento de vítimas.

Por meio de cada uma destas estratégias o MOVICE tem desenvolvido diversas ações entre as que se destacam: uso de instâncias jurídicas nacionais e internacionais na denúncia de crimes contra os direitos humanos; o seguimento e a permanente atualização de uma base de dados sobre os diversos crimes realizados pelo Estado, reunindo testemunhas, provas forenses e outros documentos comprobatórios; a criação de um centro de memória histórica e documentação que permita um diálogo público sobre a verdade histórica no país; a conformação de uma comissão ética autônoma formada por membros internacionais de diversos continentes com o objetivo de realizar ações de pesquisa e esclarecimento histórico ${ }^{7}$; oficinas de acompanhamento regional para incentivar a organização e ação das vítimas; a execução de campanhas internacionais de solidariedade com as vítimas, entre outras.

Esse conjunto de ações do movimento pode ser entendido dentro do que Tilly, McAdam e Tarrow (2009) definem como repertórios dos movimentos sociais, explicados como números limitados de desempenhos alternativos historicamente estabelecidos ligando reivindicadores a objetos de reivindicação. Segundo os autores, a eficácia de um repertório deriva basicamente de sua novidade, assim como de criar exemplos de desordem pública que são custosos aos interesses estabelecidos.

Nessa linha de ideias, ressaltamos que o MOVICE apresenta um repertório vasto que vai desde o seguimento e apoio a processos jurídicos através de estruturas nacionais e internacionais até marchas, protestos simbólicos e outras ações vistas como mais radicais. Muitas das suas atuações, nessa gama ampla que compõe o seu repertório, têm possibilitado, principalmente, a visibilidade das vítimas a um nível nacional e

7 A iniciativa da comissão Ética do MOVICE é uma proposta alternativa e independente em relação àquela estabelecida pela "Comisión Nacional de Reparación y Reconciliación" criada pela lei no 975 de 2005. A comissão governamental objetiva contribuir a garantir às vítimas acesso à verdade, justiça, reparação e não-repetição através de políticas públicas em um contexto de justiça transicional para promover a convivência pacífica e a reconciliação. O MOVICE busca ampliar esta proposta abrangendo as vítimas do Estado. (COMISSIÓN..., 2010). 
internacional que evidencia a emergência de um processo de solidariedade que tem se atrelado, de diversas formas, nas oito estratégias do movimento.

No nível da comunicação, é de ressaltar que o MOVICE tem utilizado, como outros grandes movimentos sociais da atualidade, as novas tecnologias da informação e, especialmente, a internet para consolidar parcerias com outros movimentos do mundo e para difundir suas denúncias, narrativas e doutrinas (MARTINS, 2009). A internet têmlhe permitido espalhar sua informação através de espaços de comunicação alternativos como blogs, jornais virtuais, páginas do coletivo e de outros movimentos afins. Dessa forma, o MOVICE vem complementando as versões sobre a realidade que as instituições oficiais difundem na mídia e, em algumas situações, tem se contraposto a elas.

Neste mesmo contexto da comunicação, é importante ressaltar que a possibilidade das vítimas falarem, denunciarem e exporem suas leituras sobre a situação do país é um fenômeno recente. O conflito interno na Colômbia tem uma historia de mais de 40 anos e a voz destas vítimas tem sido pouco escutada e, muitas vezes, simplesmente ignorada. Por isso as Tecnologias da Informação e Comunicação (TIC) abriram uma nova estratégia de atuação para o MOVICE e, em geral, para todos os movimentos sociais ao possibilitar-lhes alcançar e impactar a opinião pública mundial, assim como ganhar legitimidade e solidariedade das distintas audiências.

As estratégias de comunicação adotadas pelo MOVICE têm-lhe permitido repudiar as acusações e as estigmatizações que o governo nacional tem-lhe imputado ao associar o movimento com a guerrilha das FARC e, frequentemente, classificá-lo como terrorista. Por esta razão o MOVICE apresenta-se sempre como uma organização independente de todas as práticas criminosas de todos os atores da violência na Colômbia enfatizando, permanentemente, sua composição multiétnica, multicultural, com diversidade de gênero, geração etc., ou seja, reafirmando a sua identidade cultural, assim como a sua identidade de vítima, como forma de distinguir-se das organizações de oposição mais radicais e que se situam à margem da lei.

Desde seus inícios, o movimento vem consolidando umas fortes parcerias internacionais utilizando as TIC, mas também graças à forma e estrutura organizativa caracterizada pelo trabalho através de "capítulos" regionais e internacionais. Os "capítulos" atuam como órgãos independentes, porém articulados entre si que permitem uma atuação local aliada com uma permanente comunicação regional, nacional e internacional. Os "capítulos" internacionais do MOVICE operam na Espanha, na 
Argentina, na França e no México, países que receberam e ainda recebem jornalistas, ativistas políticos e membros de organizações que fazem parte do MOVICE tanto em viagens curtas com objetivos pedagógicos de capacitação ou diálogo, quanto como destino de refugiados políticos que tiveram que sair da Colômbia para proteger sua integridade e vida. A ampla presença de membros do MOVICE nesses países facilitou o desenvolvimento dessas alianças internacionais.

Utilizando seus vínculos sociais e as parcerias em diversas partes do mundo, o Movimento de Vítimas tem realizado mobilizações simultâneas em diferentes países conseguindo, desta forma, tornar-se mais conhecido e fortalecer-se, assim como respaldar atuações locais relacionadas com o repudio à violência e aos crimes contra os direitos humanos. Uma das ações simultâneas de maior reconhecimento público foi a Marcha do dia 6 de Março de 2008 convocada pelo movimento em rechaço aos crimes contra os direitos humanos realizadas pelas organizações paramilitares e pelas atuações do Estado colombiano. Essa marcha aconteceu um mês depois de uma Marcha Nacional convocada pelo governo de Álvaro Uribe Velez em repudio às FARC. Por sua oposição às atuações estatais, a marcha do MOVICE foi desaprovada pelo governo, assim como deslegitimada na mídia ao se afirmar que era convocada pela guerrilha das FARC. Embora o movimento tenha enfrentado todas essas dificuldades, ele conseguiu mobilizar mais de um milhão de pessoas nas principais cidades do país e outros milhares de participantes em 60 cidades do mundo (BBC, 2010).

Mas além das marchas e mobilizações simbólicas, o MOVICE tem conseguido denunciar, julgar e condenar as atuações do Estado colombiano utilizando instâncias internacionais como a Corte Interamericana de Direitos Humanos, a Anistia Internacional, entre outras. Recentemente a Corte Interamericana condenou o Estado colombiano pela morte do ex-senador do partido político de oposição da Unión Patriótica $^{8}$, Manuel Cepeda Vargas, acontecida em 1994. Esta decisão representa um caso emblemático porque esta é a primeira vez na história da Colômbia em que o Estado é condenado por ser responsável direito de um crime de lesa Humanidade. Seguindo a

8 A Unión Patriótica foi um partido de oposição que surgiu do processo de diálogo entre o governo colombiano na presidência de Belisario Betancur e a guerrilha das FARC na década de $1980 \mathrm{com}$ o objetivo de permitir à guerrilha o direito dela se incorporar à vida civil. Mas o rompimento dos diálogos motivado pelo não cumprimento dos acordos por ambas as partes gerou uma situação complexa que resultou no assassinato de quase todos os membros do partido, entre os quais se contavam dois candidatos presidenciais, onze prefeitos, sessenta e nove congressistas e mais de três mil dirigentes e milhares de militantes de base, assim como foram registrados mais de mil desaparecidos e "muitos outros que vi que tiveram que sair do país ou trocar sua identidade para proteger suas vidas" (CEPEDA, 2006; GÓMEZ, 2010).

Em Debat: Rev. Dig., ISSNe 1980-3532, Florianópolis, n. 6, p. 230-245, jul-dez, 2011. 
mesma linha do caso do ex-senador Cepeda, a Corte Interamericana avalia, atualmente, o caso completo da UP como o exemplo de um genocídio político por parte do Estado colombiano, ação que foi interposta pelo MOVICE na instância internacional.

Esse tipo de ações têm permitido ao movimento ganhar reconhecimento nacional e internacional, contribuindo não apenas para que ele se posicione como uma força de oposição clara do governo atual, mas principalmente ao tornar evidentes as contradições e tensões existentes dentro do modelo democrático hegemônico.

\section{Um projeto contra-hegemônico fundamentado no valor da memória}

Queremos destacar a forma com que o MOVICE posiciona a memória das vítimas como uma estratégia alternativa ao projeto de identidade nacional e à democracia defendida pelo Estado nas últimas décadas. Entendemos que essa análise pode ser feita desde uma abordagem pós-colonial dos movimentos sociais no sentido usado por Costa (2008, p. 5) o, uma abordagem pós-colonial permite e promove uma reinterpretação da história moderna, reinserindo e reinscrevendo o colonizado na modernidade, não no sentido do "outro" como sinônimo de atraso, do tradicional e da "falta", mas como parte constitutiva essencial daquilo que foi construído, discursivamente, como moderno (COSTA, 2008). A partir deste marco teórico, entendemos que a luta pela memória que o MOVICE promove tem uma dupla conotação: por uma parte, atua no sentido da reconstrução da história nacional colombiana, incluindo a voz e as lembranças das vítimas que têm participado ativamente na sua configuração; e, por outro lado, atua ao exigir o reconhecimento das relações de poder e as assimetrias que têm consolidado as estratégias de colonização dentro da democracia colombiana para, assim, poder transformá-las.

Analisemos com maior atenção a primeira conotação. A reconstrução da história nacional incluindo a voz e a lembrança das vítimas é uma luta pelo reconhecimento do papel que, como oprimidos ou colonizados, estes atores sociais têm desenvolvido no processo de formação da nação colombiana e da consolidação das liberdades e comodidades adquiridas por alguns. Ainda que o governo nacional dos últimos oito anos, encabeçado por Álvaro Uribe Vélez como presidente, tenha reafirmado constantemente seus avanços nas áreas de segurança, governabilidade e qualidade de vida dos colombianos, muitas destas conquistas têm sido fundamentadas sobre os 
sacrifícios e inclusive a morte de muitos destes colombianos, como nos lembra o MOVICE. E como Costa (2008) descreve, esse tipo de sacrifícios, que os nãohegemônicos devem fazer para sustentar a emancipação dos outros, evidenciam o que ele chama "falácia desenvolvimentista".

Com estas reivindicações, o MOVICE busca uma identidade nacional mais ampla, na qual se reconheça um NÓS abrangente e pluralista com direito e legitimidade para recordar a sua própria história. Um "nós” em que caibam os que até agora têm sido denominados "outros". A luta do movimento, desta forma, é por uma radicalização da noção de igualdade social como descreve Grosfoguel (2008), que afirma que a ideia é alargar a noção de igualdade à todas as relações de opressão, sejam elas raciais, de classe, sexuais ou de gênero e, seguindo o discurso do MOVICE, as propiciadas pelo esquecimento.

A segunda conotação comentada, por sua parte, refere-se a essas relações de poder, de opressão, sobre as quais se erige a modernidade. Neste mesmo sentido, Grosfoguel (2008) ressalta que não se trata de entendê-las de forma dicotômica, mas de superar todo um "sistema mundo euro-norteamericano/moderno/capitalista/colonial/patriarcal que encontra-se também subjetivado na consciência dos oprimidos". O trabalho em prol da memória, da organização, da legitimação e do reconhecimento das vítimas que o MOVICE faz caminha neste mesmo rumo. Trata-se então de incluir esse outro oprimido, negado, esquecido, e edificar um processo de diversidade anticapitalista descolonial universal e radical (GROSFOGUEL, 2008).

Para concluir, gostaríamos de reforçar os aspectos de riqueza e originalidade obtidos pela luta do MOVICE no contexto colombiano, assim como em meio aos clássicos movimentos sociais de reivindicação de vítimas de conflitos armados e políticos. Sem dúvida a identidade multicultural e distinta obtida pelo grupo como vítimas de crimes de Estado, assim como seu amplo repertório de atuação, possibilitaram-lhe gerar um conjunto de solidariedades nacionais e internacionais através das quais o MOVICE tem conseguido legitimar suas atuações e denunciar, permanentemente, as tensões e conflitos existentes dentro do Estado democrático colombiano.

Finalmente, este é o desafio dos movimentos sociais, o de evidenciarem as formas de colonização e opressão sobre as quais se erigiu a "modernidade" e tentar, desta forma, reinventar e reconstruir, conjuntamente com outros agentes sociais, uma 
nova modernidade descolonizada, mais justa e baseada nos princípios da verdade, da justiça, da reparação e da memória. "como 'desconstrução' da polaridade West/Rest constituída, historicamente, no âmbito da relação colonial, mas que se perpetua mesmo depois de extinto o colonialismo como forma de orientar a produção do conhecimento e a intervenção política”.

Nesse sentido, uma abordagem pós-colonial permite e promove uma reinterpretação da história moderna, reinserindo e reinscrevendo o colonizado na modernidade, não no sentido do "outro" como sinônimo de atraso, do tradicional e da "falta", mas como parte constitutiva essencial daquilo que foi construído, discursivamente, como moderno (COSTA, 2008). A partir deste marco teórico, entendemos que a luta pela memória que o MOVICE promove tem uma dupla conotação: por uma parte, atua no sentido da reconstrução da história nacional colombiana, incluindo a voz e as lembranças das vítimas que têm participado ativamente na sua configuração; e, por outro lado, atua ao exigir o reconhecimento das relações de poder e as assimetrias que têm consolidado as estratégias de colonização dentro da democracia colombiana para, assim, poder transformá-las.

Analisemos com maior atenção a primeira conotação. A reconstrução da história nacional incluindo a voz e a lembrança das vítimas é uma luta pelo reconhecimento do papel que, como oprimidos ou colonizados, estes atores sociais têm desenvolvido no processo de formação da nação colombiana e da consolidação das liberdades e comodidades adquiridas por alguns. Ainda que o governo nacional dos últimos oito anos, encabeçado por Álvaro Uribe Vélez como presidente, tenha reafirmado constantemente seus avanços nas áreas de segurança, governabilidade e qualidade de vida dos colombianos, muitas destas conquistas têm sido fundamentadas sobre os sacrifícios e inclusive a morte de muitos destes colombianos, como nos lembra o MOVICE. E como Costa (2008) descreve, esse tipo de sacrifícios, que os nãohegemônicos devem fazer para sustentar a emancipação dos outros, evidenciam o que ele chama "falácia desenvolvimentista".

Com estas reivindicações, o MOVICE busca uma identidade nacional mais ampla, na qual se reconheça um NÓS abrangente e pluralista com direito e legitimidade para recordar a sua própria história. Um "nós" em que caibam os que até agora têm sido denominados "outros". A luta do movimento, desta forma, é por uma radicalização da noção de igualdade social como descreve Grosfoguel (2008), que afirma que a ideia é alargar a noção de igualdade à todas as relações de opressão, sejam elas raciais, de 
classe, sexuais ou de gênero e, seguindo o discurso do MOVICE, as propiciadas pelo esquecimento.

A segunda conotação comentada, por sua parte, refere-se a essas relações de poder, de opressão, sobre as quais se erige a modernidade. Neste mesmo sentido, Grosfoguel (2008) ressalta que não se trata de entendê-las de forma dicotômica, mas de superar todo um "sistema mundo euro-norte americano/moderno/capitalista/colonial/patriarcal que encontra-se também subjetivado na consciência dos oprimidos". O trabalho em prol da memória, da organização, da legitimação e do reconhecimento das vítimas que o MOVICE faz caminha neste mesmo rumo. Trata-se então de incluir esse outro oprimido, negado, esquecido, e edificar um processo de diversidade anticapitalista descolonial universal e radical (GROSFOGUEL, 2008).

Para concluir, gostaríamos de reforçar os aspectos de riqueza e originalidade obtidos pela luta do MOVICE no contexto colombiano, assim como em meio aos clássicos movimentos sociais de reivindicação de vítimas de conflitos armados e políticos. Sem dúvida a identidade multicultural e distinta obtida pelo grupo como vítimas de crimes de Estado, assim como seu amplo repertório de atuação, possibilitaram-lhe gerar um conjunto de solidariedades nacionais e internacionais através das quais o MOVICE tem conseguido legitimar suas atuações e denunciar, permanentemente, as tensões e conflitos existentes dentro do Estado democrático colombiano.

Finalmente, este é o desafio dos movimentos sociais, o de evidenciarem as formas de colonização e opressão sobre as quais se erigiu a "modernidade" e tentar, desta forma, reinventar e reconstruir, conjuntamente com outros agentes sociais, uma nova modernidade descolonizada, mais justa e baseada nos princípios da verdade, da justiça, da reparação e da memória. 


\section{Referências Bibliográficas}

AMNISTÍA INTERNACIONAL. Violencia Política en Colombia: Mito y Realidad. Madrid: Edai, 1994.

BBC. Colombia: miles marcharon. Matéria publicada em 7 mar. 2008. Disponível em: http://news.bbc.co.uk/hi/spanish/latin_america/newsid_7282000/7282610.stm. Acesso em: 15 jul. 2010.

CEPEDA, Manuel. Genocidio político el caso de la Unión Patriótica en Colombia. Revista Cetil, Bogotá, v. 2, p. 101-112, 2006.

COMISIÓN NACIONAL DE REPARACIÓN Y RECONCILIACIÓN. Disponível em: www.cnrr.org.co. Acesso em 21 jul. 2010

COSTA, Sérgio. Muito além da diferença: (im)possibilidades de uma teoria social póscolonial. 2008. Cholonautas - Biblioteca Virtual. Disponível em $<$ http://www.cholonautas.edu.pe $>$. Acesso em 20 de julho de 2010.

GROSFOGUEL, Ramón. Para descolonizar os estudos de economia política e os estudos pós-coloniais: transmodernidade, pensamento de fronteira e colonialidade global. Revista Crítica de Ciências Sociais, Coimbra, v. 80, p. 115-147, mar. 2008.

HALL, Stuart. Da diáspora: identidades e mediações culturais. Belo Horizonte: Ed UFMG, 2003.

JARAMILLO, Daniel. La relación del Estado Colombiano con el fenómeno Paramilitar: por el esclarecimiento histórico. Análisis Político: Instituto de Estudios Políticos y Relaciones Internacionales IEPRI. Universidad Nacional de Colombia, Bogotá, n. 53, p. 58-76, jan. 2005.

KAUCHAKJE, Samira. Solidariedade política e constituição de sujeitos: a atualidade dos movimentos sociais. Sociedade e Estado, Brasília, v. 23, n. 3, p. 667-696, set.-dez. 2008.

MARTINS, Paulo Henrique. Redes sociais: entre o simplismo da ideologia utilitarista e a complexidade das mudanças sócio-históricas contemporâneas. In: MARTINS, Paulo Henrique; MEDEIROS, Rogério. América latina e Brasil em perspectiva. Recife: Ed UFPE, 2009. p. 16-50. 
MEDINA Gallego, Carlos. Autodefensas, Paramilitares y Narcotráfico en Colombia. Bogotá: Rodríguez Quito Editores, 1990.

MELUCCI, Alberto. A invenção do presente; movimentos sociais nas sociedades complexas. Petrópolis: Vozes, 2001.

MOVICE. Disponível em: www.movimientodevictimas.org. Acesso em 10 jul. 2010.

MUNANGA, Kabengele. Diversidade, etnicidade, identidade e cidadania. Palestra proferida no $1^{\mathrm{o}}$ Seminário de Formação Teórico Metodológica. Disponível em: $<$ http://www.acaoeducativa.org.br/downloads/05diversidade.pdf $>$. Acesso em 20 jul. 2010.

SCHERER-WARREN, Ilse. Das mobilizações às redes de movimentos sociais. Sociedade e Estado, Brasília, v. 21, n. 1, p. 109-130, 2006.

. Movimentos sociais na América Latina: revisitando as teorias. Rio de Janeiro:

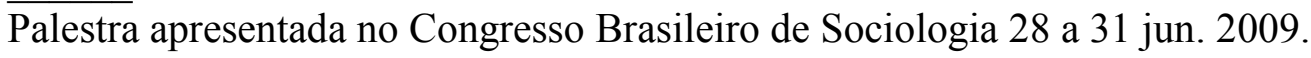

SUAREZ, Gomez Andrei. The genocide of the Unión Patriótica and the hyperreal Writing of Colombia in US foreign policy (1985-2008). Texto apresentado na 60th Political Studies Association Annual Conference, Edinburgh. 2010. Disponível em: $<$ http://www.psa.ac.uk/journals/pdf/5/2010/1279 1160.pdf $>$. Acesso em 20 jul. 2010.

TILLY, Charles; MCADAM, Doug; TARROW, Sidney. Para mapear o confronto político. Lua Nova, São Paulo, v. 76, p. 11-48, 2009.

TOBÓN, Alfonso; GRANADA, Soledad; RESTREPO, Jorge. Neoparamilitarismo en Colombia: una herramienta conceptual para la interpretación de dinámicas recientes del conflicto armado colombiano. In: RESTREPO, Jorge; APONTE, David (Comp.). Guerra y violencias en Colombia: herramientas e Interpretaciones. Bogotá: Pontificia Universidad Javeriana, CERAC, 2009. p. 467-499. 